\section{Kidney \\ Blood Pressure \\ Research}

Kidney Blood Press Res 2013;37:95-102

DOI: 10.1159/000343404

Published onime: Ivarch 31, 2013

(C) 2013 S. Karger AG, Basel

www.karger.com/kbr

1423-0143/13/0372-0095\$38.00/0

This is an Open Access article licensed under the terms of the Creative Commons AttributionNonCommercial-NoDerivs 3.0 License (http://www.karger.com/OA-license), applicable to the online version of the article only. Distribution for non-commercial purposes only.

\title{
Angiotensinogen Polymorphisms and Post-Transplantation Diabetes Mellitus in Korean Renal Transplant Subjects
}

\author{
Sul ra Lee ${ }^{a}$ Joo Young Moon ${ }^{a}$ Sang Ho Lee ${ }^{a}$ Chun Gyoo Ihm ${ }^{\text {a }}$ Tae Won Lee \\ Su Kang Kim ${ }^{b}$ Joo-Ho Chung ${ }^{b}$ Sun Woo Kang ${ }^{c}$ Tae Hee Kim ${ }^{c}$ Seok Ju Park ${ }^{c}$ \\ Yeong Hoon Kim ${ }^{c}$ Kyung Hwan Jeonga
}

aDivision of Nephrology, School of Medicine, Kyung Hee University, Seoul, 'bohwang Medical Research Institute, School of Medicine, Kyung Hee University, Seoul, 'Division of Nephrology, School of Medicine, Inje University, Busan

\section{Key Words}

$A C E \cdot A G T \cdot$ Polymorphism • Post-transplantation diabetes mellitus • Renal transplantation

\begin{abstract}
Background: Post-transplant diabetes mellitus (PTDM) is a common and serious metabolic complication. Genetic polymorphisms of angiotensin-converting enzyme (ACE) and angiotensinogen (AGT) genes have been reported to be related to diabetes mellitus and insulin sensitivity; however, the role of these genes in the development of PTDM is not known. For this purpose, we investigated the association of ACE and AGT genetic polymorphisms with PTDM. Methods: A total of 302 subjects without previously diagnosed diabetes who had received kidney transplants were included. One $A C E$ single nucleotide polymorphism (SNP) (rs4291) and two AGT SNPs (rs 699 and rs 4762) were genotyped from genomic DNA with direct sequencing. Results: PTDM developed in 49 (16.2\%) of 302 subjects. Subjects in the PTDM were older than those in the non-PTDM. There was a significant difference between the two groups in tacrolimus use $(p=0.03)$. Of the three SNPs, the rs4762 of the AGT gene was significantly associated with the development of PTDM in the dominant models $(p=0.03)$ after adjusting for age and tacrolimus usage. Conclusions: AGT gene rs4762 polymorphisms may serve as genetic markers for the development of PTDM. The exact molecular mechanisms still need to be clarified.
\end{abstract}




\section{Kidney Blood Pressure Research}

Lee/Moon/Lee/Ihm/Lee/Kim et al.: AGT Gene Polymorphism and PTDM

\section{Introduction}

Post-transplant diabetes mellitus (PTDM) is a common and serious metabolic complication after kidney transplantation. Transplant recipients are at a particularly high risk of developing PTDM as a consequence of factors that are in addition to those that affect the general population, including the use of immunosuppressive agents in transplant management protocols. In addition, PTDM is thought to develop in response to a relative insulin deficiency resulting from increased insulin resistance or impaired insulin production, or a combination of both [1]. The risk factors for PTDM reportedly include old age, hepatitis $\mathrm{C}$ infection, and the use of corticosteroids and tacrolimus [2,3]. Previous studies have found that several genetic factors may influence the development of PTDM. The TCF7L2 and SLC30A8 genetic variations are associated with the development of PTDM in renal allograft recipients $[4,5]$.

Recently, the renin-angiotensin system (RAS) has attracted interest with regard to the pathogenesis of insulin resistance and DM in the general population. Several studies have suggested that angiotensin (Ang) II may affect glucose metabolism through insulin signaling pathways, blood flow, oxidative stress, and adipogenesis [6, 7]. Angiotensinogen (AGT) is the initial component of the RAS and a precursor to both Ang I and Ang II. A possible role for AGT in the development of DM is unclear; however, AGT gene variants of rs699 (Met235Thr) that were previously shown to be associated with AGT levels were found to be associated with insulin sensitivity in a recent study [8]. It has been also reported that the AGT (rs699) polymorphism is related to visceral obesity and hyperinsulinemia in obese Japanese women [9]. Additionally, rs4762-rs699 haplotype of AGT was also reported to play the important role in the increase risk for pregnancy induced hypertension [10]. Angiotensin converting enzyme (ACE), a key enzyme in the RAS, catalyzes the conversion of Ang I to Ang II in the liver and inactivates bradykinins in many tissues. In the GenHAT study [11], an ACE promoter polymorphism (rs4291) was associated with lower fasting glucose levels. Many reports suggest that genetic variants of $A C E$ or $A G T$ influence the development of DM and insulin resistance or sensitivity. However, whether the genetic polymorphisms of $A C E$ and $A G T$ are involved in the pathogenesis of PTDM has not yet been clarified.

We hypothesized that the polymorphisms of ACE and AGT play an important role in determining PTDM susceptibility in renal transplant subjects. Polymorphisms/genes associated with diabetes and insulin sensitivity and other related disease in published studies were treated as candidates for PTDM. Therefore, in the present study, we genotyped one ACE SNP (rs4291 in promoter -262) and two AGT SNPs (rs 699 in Met235Thr and rs 4762 in Thr207Met), and investigated the association between polymorphisms in the ACE and $A G T$ genes and the development of PTDM.

\section{Materials and Methods}

\section{Study Design and Population}

A total of 302 renal transplant recipients were recruited from 2000 to 2009 at three transplant centers in the Republic of Korea (Kyung Hee University Medical Center, Kyung Hee University Hospital at Gangdong, and Inje University Busan Paik Hospital). In this study, we retrospectively examined the genetic polymorphism in stored blood and reviewed the medical record in the renal transplant recipients. All studies were performed according to the Declaration of Helsinki guidelines and written informed consent was obtained from each subject. This study was approved by the ethics review committees of all three transplant centers.

As in our previous study [12], the subjects were classified into two groups according to the development of PTDM. PTDM was diagnosed according to the American Diabetes Association guidelines [13] after the third post-transplantation month. These criteria were fasting blood glucose levels $\geq 126 \mathrm{mg} / \mathrm{dl}$ (7.0 mmol/l); or symptoms of diabetes mellitus plus plasma glucose concentrations $\geq 200 \mathrm{mg} / \mathrm{dl}$ (11.1 mmol/l) at any time of day; or 2-h post-load glucose $\geq 200 \mathrm{mg} / \mathrm{dl}$ (11.1 mmol/l) during an oral glucose tolerance test; or insulin 


\section{Kidney Blood Pressure Research}

Table 1. Primer Sequences and Expected Product Sizes

\begin{tabular}{|c|c|c|c|c|c|}
\hline $\begin{array}{l}\text { Chromo- } \\
\text { some }\end{array}$ & Gene & $\begin{array}{l}\text { SNP } \\
\text { locus }\end{array}$ & & Sequence (5'-3') & $\begin{array}{l}\text { Products size } \\
\text { (bp) }\end{array}$ \\
\hline 17 & $A C E$ & $\begin{array}{c}\text { rs4291 } \\
\text { Promoter }-262\end{array}$ & $\begin{array}{c}\text { sense } \\
\text { antisense }\end{array}$ & $\begin{array}{l}\text { ACCATGGCCTGGTGAAGAAG } \\
\text { GGTTATAAAACCCGACACACC }\end{array}$ & 444 \\
\hline 1 & $A G T$ & $\begin{array}{c}\text { rs } 699 \\
\text { Met235Thr }\end{array}$ & $\begin{array}{l}\text { sense } \\
\text { antisense }\end{array}$ & $\begin{array}{l}\text { TGTACAGGGCCTGCTAGTGG } \\
\text { ACTGGCTGATCTCAGCTACACA }\end{array}$ & 369 \\
\hline 1 & $A G T$ & $\begin{array}{l}\text { rs } 4762 \\
\text { Thr207Met }\end{array}$ & $\begin{array}{c}\text { sense } \\
\text { antisense }\end{array}$ & $\begin{array}{l}\text { СTCTCTCTATCTGGGAGCCTTG } \\
\text { CAATCTTCTCAGCAGCAACATC }\end{array}$ & 323 \\
\hline
\end{tabular}

and/or oral hypoglycemic agents that were required for more than three months. Subjects were excluded if they had a history of diabetes before transplantation or if they had a severe metabolic or infectious disease. We included the patients with normal fasting glucose levels and HbA1c levels before transplantation. Patients were excluded if they had impaired fasting glucose levels (fasting plasma glucose 100-125 mg/ $\mathrm{dL}$ ). In this study, we analyzed the following demographic data: age, sex, body mass index (BMI) at the time of transplantation, human leukocyte antigen mismatching, hepatitis C infection, acute rejection episodes, follow up levels of creatinine and the types of immunosuppressive agents used.

\section{SNP Selection and Genotyping}

We selected SNPs in the ACE and AGT gene using the dbSNP database (http://www.ncbi.nlm.nih.gov/ SNP) and that of the International Hapmap Project (http://www.hapmap.org/index.html). We excluded SNPs with unknown heterozygosity and a minor allele frequency below $5 \%$ in the general population. We included SNPs that were previously reported to be associated with diabetes or insulin sensitivity [8]. One ACE SNP (rs4291) and two AGT SNPs (rs 699 and rs 4762) were finally selected and used for genotyping the subjects.

Blood samples were collected from each subject and then stored in a $-20^{\circ} \mathrm{C}$ refrigerator. Genomic DNA was extracted from the peripheral blood using a DNA extraction kit (Qiagen, Tokyo, Japan). SNP genotyping was conducted by direct sequencing. Genomic DNA was amplified with specific primers for the one ACE and two AGT gene SNPs (Table 1). The amplified products were sequenced with an ABI PRISM 3730XL automatic sequencer (PE Applied Biosystems, Foster City, CA, USA), and the sequence data were analyzed with SeqManII software (DNASTAR Inc., Madison, WI, USA).

\section{Statistical Analysis}

We analyzed the one $A C E$ and two AGT SNPs in each of the 302 renal transplant subjects. SNPStats (http://bioinfo.iconcologia.net/index.php?module=Snpstats) was used to analyze genetic data. Allelic frequencies were compared between the two groups with the $\chi^{2}$ test. In the association study between SNPs and PTDM, we calculated the odds ratios (OR), 95\% CI, and $p$-values with SNPstats, HapAnalyzer version 1.0, and SNPanalyzer (ISTECH, Goyang, Korea), respectively. For multiple logistic regression analyses to determine the associations between single SNPs and PTDM, we used multiple inheritance models, including codominant 1 (major allele homozygotes vs. heterozygotes), codominant 2 (major allele homozygotes vs. minor allele homozygotes), dominant (major allele homozygotes vs. minor allele homozygotes plus heterozygotes), and recessive (major allele homozygotes plus heterozygotes vs. minor allele homozygotes) models. A linkage disequilibrium (LD) block of polymorphisms was tested with Haploview version 4.1 (http://www.broadinstitute.org/haploview/haploview). Clinical characteristics were compared with Student's unpaired $t$-test and the $\chi^{2}$ test. Values of $p<0.05$ were considered statistically significant.

\section{Results}

\section{Clinical Characteristics}

We enrolled 302 renal transplant recipients. The mean follow-up duration for all 302 subjects was 87.91 months (87.91 \pm 78.23 months), and 49 subjects $(16.2 \%)$ developed PTDM. The clinical parameters of the transplant recipients are shown in Table 2. The mean ages at transplantation of the non-PTDM and PTDM subjects were 38.10 \pm 11.21 years and 


\section{Kidney \\ Blood Pressure Research}

Table 2. Comparison of Clinical Factors Between PTDM and non-PTDM Groups

\begin{tabular}{lccc}
\hline Variable & PTDM $(\mathrm{n}=49)$ & Non-PTDM $(\mathrm{n}=253)$ & $p$ \\
\hline Age at transplantation (years) & $45.18 \pm 9.39$ & $38.10 \pm 11.21$ & $<\mathbf{0 . 0 1}$ \\
Sex & & & \\
Male & 26 & 155 & 0.28 \\
Female & 23 & 98 & \\
BMI $\left(\mathrm{kg} / \mathrm{m}^{2}\right)$ & $22.26 \pm 3.31$ & $22.48 \pm 3.45$ & 0.71 \\
HLA total mismatches, $\mathrm{n}$ & $3.00 \pm 1.55$ & $3.27 \pm 1.51$ & 0.28 \\
Hepatitis C infection, $\mathrm{n}$ & 0 & 6 & 0.25 \\
Acute rejection with steroid boluses, $\mathrm{n}$ & 13 & 49 & 0.25 \\
Tacrolimus usage, $\mathrm{n}$ & 23 & 78 & $\mathbf{0 . 0 3}$ \\
Serum Creatinine (mg/dl) & & & \\
6 mos. after transplantation & $1.31 \pm 0.58$ & $1.31 \pm 0.46$ & 0.95 \\
12 mos. after transplantation & $1.30 \pm 0.37$ & $1.36 \pm 0.85$ & 0.64 \\
\hline PTDM, posttransplantation diabetes group; non-PTDM, non-posttransplantation diabetes group; \\
Bold characters represent statistically significant values
\end{tabular}

Table 3. Allele Frequencies of Three SNPs of the ACE and AGT Genes in PTDM and Non-PTDM Subjects

\begin{tabular}{lccccc}
\hline SNP Gene & Allele & PTDM; $(\%)$ & Non-PTDM; $(\%)$ & OR (95\% CI) & $p$ \\
\hline rs4291 & A & $61(65 \%)$ & $277(56 \%)$ & $0.69(0.44-1.10)$ & 0.12 \\
$A C E$ & $\mathrm{~T}$ & $33(35 \%)$ & $215(44 \%)$ & & \\
rs 699 & $\mathrm{C}$ & $70(71 \%)$ & $399(80 \%)$ & $1.61(0.98-2.63)$ & 0.05 \\
$A G T$ & $\mathrm{~T}$ & $28(29 \%)$ & $99(20 \%)$ & & \\
rs 4762 & $\mathrm{C}$ & $78(81 \%)$ & $456(90 \%)$ & $2.10(1.16-3.79)$ & $\mathbf{0 . 0 1}$ \\
AGT & $\mathrm{T}$ & $18(19 \%)$ & $50(10 \%)$ & \\
\hline \multicolumn{7}{l}{ PTDM, posttransplantation diabetes group; non-PTDM, non-posttransplantation diabetes group; OR, } \\
\multicolumn{7}{l}{ odds ratio; CI, confidence interval; Bold characters represent statistically significant values } \\
\hline
\end{tabular}

$45.18 \pm 9.39$ years, respectively. Subjects in the PTDM group were significantly older than those in the non-PTDM group $(p<0.01)$. The sex ratio between the two groups was similar $(p=0.28)$. BMI, HLA mismatches, the frequency of hepatitis C-positivity, and episodes of acute rejection did not differ between the two groups; however, in the PTDM group, tacrolimus use as an immunosuppressive agent was significantly higher $(p=0.03)$. However, two groups were statistically indistinguishable in the levels of serum creatinine after transplantation at 3 months and 6 months.

\section{Genetic Associations between One ACE and Two AGT SNPs and PTDM}

Genetic associations between the one ACE and two AGTs SNPs and PTDM in subjects that had undergone renal transplants were investigated. Genotyping success rates were $97.02 \%$, $98.68 \%$, and $99.67 \%$ for rs 4291 , rs 699 , and rs 4762 , respectively. The genotype distributions of the three polymorphic SNPs were all in Hardy-Weinberg equilibrium ( $p>0.05)$. The allele frequencies are shown in Table 3. The allele frequency of the one SNP of AGT (rs4762) was statistically associated with a risk of PTDM (OR $=2.10 ; 95 \% \mathrm{CI}: 1.16-3.79 ; p=0.01)$, where the presence of the T allele increased the risk of PTDM in kidney transplantation patients.

In the univariate analyses, age and use of tacrolimus were significantly associated with the development of PTDM. Therefore, we performed multiple logistic regression analysis to analyze genotype data for associations with PTDM, with adjustment for age and the use of tacrolimus. Table 4 shows that the effect of genotype on PTDM remained significant after these multiple logistic regression adjustments. The rs4762 of the AGT gene was significantly associated with the development of PTDM. We observed significant higher distribution of $\mathrm{C} / \mathrm{T}$ plus $\mathrm{T} / \mathrm{T}$ genotypes in PTDM subjects than in control subjects under a dominant model 


\section{Kidney Blood Pressure Research}

Table 4. Logistic Regression Analysis of the ACE and AGT Polymorphisms in PTDM and Non-PTDM Subjects Adjusted for Age and Tacrolimus Usage

\begin{tabular}{cccccccc}
\hline Gene & SNP & Genotype & $\begin{array}{c}\text { PTDM } \\
\text { n (\%) }\end{array}$ & $\begin{array}{c}\text { Non-PTDM } \\
\text { n (\%) }\end{array}$ & Models & OR (95\% CI) & $p$ \\
\hline \multirow{2}{*}{$A C E$} & rs4291 & A/A & $20(42.5 \%)$ & $75(30.5 \%)$ & Codominant1 & $0.57(0.28-1.15)$ & 0.11 \\
& & T/A & $21(44.7 \%)$ & $127(51.6 \%)$ & Codominant2 & $0.51(0.18-1.42)$ & 0.20 \\
& & T/T & $6(12.8 \%)$ & $44(17.9 \%)$ & Dominant & $0.56(0.29-1.09)$ & 0.08 \\
& & & & Recessive & $0.61(0.24-1.55)$ & 0.28 \\
AGT & rs 699 & C/C & $24(49 \%)$ & $157(63 \%)$ & Codominant1 & $1.68(0.87-3.26)$ & 0.12 \\
& & T/C & $22(44.9 \%)$ & $85(34.1 \%)$ & Codominant2 & $3.58(0.78-16.38)$ & 0.10 \\
& & T/T & $3(6.1 \%)$ & $7(2.8 \%)$ & Dominant & $1.80(0.95-3.42)$ & 0.07 \\
& & & & & Recessive & $2.89(0.65-12.81)$ & 0.19 \\
AGT & rs 4762 & C/C & $37(69.8 \%)$ & $202(79.5 \%)$ & Codominant1 & $1.99(0.95-4.15)$ & 0.06 \\
& & C/T & $14(26.4 \%)$ & $47(18.5 \%)$ & Codominant2 & $5.10(0.61-42.33)$ & 0.13 \\
& & T/T & $2(3.8 \%)$ & $5(2.0 \%)$ & Dominant & $\mathbf{2 . 1 5 ( 1 . 0 6 - 4 . 3 6 )}$ & $\mathbf{0 . 0 3}$ \\
& & & & & Recessive & $4.34(0.53-35.63)$ & 0.18 \\
\hline
\end{tabular}

PTDM, posttransplantation diabetes group; non-PTDM, non-posttransplantation diabetes group; OR, odds ratio; CI, confidence interval; Models, Multiple inheritance models, namely codominant 1 (major allele homozygotes vs. heterozygotes), codominant 2 (major allele homozygotes vs. minor allele homozygotes), dominant (major allele homozygotes vs. minor allele homozygotes plus heterozygotes), and recessive (major allele homozygotes plus heterozygotes vs. minor allele homozygotes) models were used for association analysis of single SNPs

$\mathrm{C} / \mathrm{C}$ vs $\mathrm{C} / \mathrm{T}+\mathrm{T} / \mathrm{T})$ with an odds ratio of 2.15 (95\% CI, 1.06-4.36; $p=0.03)$. The significance was permitted after controlling for covariates age and tacrolimus usage.

We then tested whether the AGT haplotype was associated with PTDM. To demonstrate pair-wise linkage disequilibrium (LD), we analyzed two SNPs and found that they were in linkage equilibrium. The D' value between AGT SNP rs699 and rs4762 was 0.652 . The $\mathrm{r}^{2}$ value between AGT SNPs rs699 and rs4762 was 0.578 .

In order to predict the functional significance of missense SNP (rs4762) in AGT gene, we performed bioinformatic software tool using PolyPhen (http://genetics.bwh.harvard.edu/ pph2/index.shtml). Result based on PolyPhen, the function and protein structure of AGT was significantly affected by the Thr207Met missense SNP (rs4762).

\section{Discussion}

PTDM is a serious metabolic complication after kidney transplantation. Multiple risk factors for the development of PTDM have been identified: type of immunosuppression, ethnicity, age, and body mass index [14]. However, PTDM can also develop without these risk factors, and even if they are present, the rate of PTDM occurrence may be influenced by genetic factors. Many studies have been performed to analyze SNPs as genetic markers. The results of the present study indicate that an AGT polymorphism (rs 4762) is associated with PTDM in Korean renal transplant patients.

The AGT gene (specifically rs4762) polymorphism, was previously reported to be associated with essential hypertension and pregnancy hypertension $[10,15]$. The association between this gene and glucose metabolism is controversial. Perhaps the mechanism underlying our finding of an association between the AGT gene and PTDM may be explained by insulin resistance. Molecular and genetic studies demonstrate a relationship between variants of the $A G T$ gene, $A G T$ gene expression, and plasma AGT levels $[16,17]$. In our study, the Thr207 Met missense SNP affects the function and protein structure of AGT. It is possible that increased plasma AGT levels and the effect of AGT gene variants increase Ang II levels inappropriately and thereby impair glucose transport mainly via the inhibition of insulin signaling [19]. However, we could not evaluate the AGT levels and/or insulin resistance in this study. The relationship between AGT gene polymorphisms and insulin resistance has been 


\section{Kidney Blood Pressure Research}

\begin{tabular}{l}
\begin{tabular}{l|l}
\hline Kidney Blood Press Res 2013;37:95-102 \\
\hline DOI: 10.1159/000343404 & O 2013 S. Karger AG, Basel
\end{tabular} \\
\hline
\end{tabular}

Published online: March 31, 2013

www.karger.com/kbr

Lee/Moon/Lee/Ihm/Lee/Kim et al.: AGT Gene Polymorphism and PTDM

reported in other studies. Takakura et al. [9] demonstrated that AGT gene polymorphisms are linked to visceral obesity and insulin resistance in obese Japanese women.

It was reported that Ang II induced mononuclear leukocyte interaction are mediated by release of several CC chemokines such as chemokine ligand 5 (CCL5) [18]. As in our previous study [12], genetic polymorphisms of the CCL5 gene were associated with PTDM. But, we could not predict any relationship between CCL5 and ACE, AGT gene in the PTDM. Further study is necessary for evaluation of relation of the RAS SNPs and cytokine such as CCL5.

Earlier studies have reported the influence of $A C E$ promoter polymorphisms on fasting glucose levels [11]. Previous data on the association between ACE polymorphisms and insulin resistance are contradictory; these studies have included limited numbers of participants and/or only used surrogate markers of insulin resistance [20, 21]. A recent study demonstrated that AGT Met235Thr (rs 699) and ACE I/D polymorphisms were linked to the increased risk of PTDM [22]; this result was not replicated in the present study. Study designs and populations may explain the contradictory results and are important to emphasize in future investigations. The previous study was performed using subjects of a different ethnicity, suggesting that the association with AGT polymorphisms may be ethnically dependent. We used a purely Korean population to eliminate false positive results due to population stratification. Furthermore, our regression approach permitted adjustment for the effects of environmental risk factors of PTDM, such as age and tacrolimus use.

Older age and tacrolimus use were significant risk factors in this study. Previous studies have consistently found that PTDM developed much more frequently in older transplant recipients than in younger recipients [23]. Tacrolimus as a main immunosuppressive drug was also shown to be a risk factor for PTDM in renal transplant patients [23]; however, the effect of $A G T$ polymorphisms on PTDM remained significant after adjustment for age and tacrolimus use. Hjelmesaeth et al showed that the risk of developing PTDM increases by $5 \%$ when the corticosteroid dose is raised by $0.01 \mathrm{mg} / \mathrm{kg} /$ day [24]. In addition, high corticosteroid doses such as steroid boluses, given for acute rejection episodes, might partly account for the development of PTDM. However, the acute rejection episodes with boluse steroid therapy were not significantly different in this study. Further studies are necessary to evaluate the association of steroid doses and development of PTDM. Previous study has reported the influence of hepatitis C virus (HCV) infection on the development of PTDM [25]. According to our results, however, the HCV infection was not different between PTDM and non-PTDM groups. Possible explanations for this discrepancy may be due to small number of HCV in our study compared to previous study.

There were several limitations to this study. First, our analysis was conducted in a relatively small sample. To confirm or refute the associations between the AGT gene and PTDM, validation studies with an adequate sample size and studies with additional SNPs not analyzed in the present study may be required. Second, we did not assay the levels of $A G T$ in vivo or examine the functional effects of the AGT polymorphisms. Further studies are necessary to elucidate whether AGT SNPs can affect the expression of AGT. Finally, we didn't performed regularly oral glucose tolerance tests before transplantation or study registration. So, preexisting impaired glucose tolerance could have led to an overestimation of PTDM incidence. We minimized overestimation by excluding PTDM when hemoglobin A1c was over $6.0 \%$, fasting plasma glucose concentration was over $126 \mathrm{mg} / \mathrm{dl}$ before transplantation. Nevertheless, this study is meaningful because this is the first study to reveal a significant association between PTDM and AGT SNP (specifically rs4762), and we suggest that these results show potential for clinical application and better explanation of PTDM episodes.

\section{Conclusion}

We examined the possible association between $A C E$ and $A G T$ gene polymorphisms and PTDM in Korean subjects who had undergone renal transplants. We found a significant 


\section{Kidney \\ Blood Pressure Research}

Lee/Moon/Lee/Ihm/Lee/Kim et al.: AGT Gene Polymorphism and PTDM

association between SNPs of the AGT gene (rs4762) and PTDM in kidney transplantation recipients. These results suggest that AGT rs4762 polymorphisms may act as genetic markers for the development of PTDM. Additional genetic studies are needed to provide an understanding of the precise mechanisms underlying the pathogenesis of PTDM in kidney transplantation patients.

\section{Conflict of Interests}

No potential conflict of interest relevant this article was reported.

\section{References}

1 van Hooff JP, Christiaans MH, van Duijnhoven EM: Evaluating mechanisms of post-transplant diabetes mellitus. Nephrol Dial Transplant 2004;19:vi8-vi12.

2 Rodrigo E, Fernandez-Fresnedo G, Valero R, Ruiz JC, Pinera C, Palomar R, Gonzalez-Cotorruelo J, GomezAlamillo C, Arias M: New-onset diabetes after kidney transplantation: Risk factors. J Am Soc Nephrol 2006;17:S291-295.

-3 Heisel 0, Heisel R, Balshaw R, Keown P: New onset diabetes mellitus in patients receiving calcineurin inhibitors: A systematic review and meta-analysis. Am J Transplant 2004;4:583-595.

-4 Kang ES, Kim MS, Kim YS, Hur KY, Han SJ, Nam CM, Ahn CW, Cha BS, Kim SI, Lee HC: A variant of the transcription factor 7-like 2 (TCF7L2) gene and the risk of posttransplantation diabetes mellitus in renal allograft recipients. Diabetes Care 2008;31:63-68.

5 Kang ES, Kim MS, Kim YS, Kim CH, Han SJ, Chun SW, Hur KY, Nam CM, Ahn CW, Cha BS, Kim SI, Lee HC: A polymorphism in the zinc transporter gene SLC30A8 confers resistance against posttransplantation diabetes mellitus in renal allograft recipients. Diabetes 2008;57:1043-1047.

-6 Muscogiuri G, Chavez AO, Gastaldelli A, Perego L, Tripathy D, Saad MJ, Velloso L, Folli F: The crosstalk between insulin and renin-angiotensin-aldosterone signaling systems and its effect on glucose metabolism and diabetes prevention. Curr Vasc Pharmacol 2008;6:301-312.

7 Kurtz TW, Pravenec M: Antidiabetic mechanisms of angiotensin-converting enzyme inhibitors and angiotensin II receptor antagonists: Beyond the renin-angiotensin system. J Hypertens 2004;22:22532261.

8 Underwood PC, Sun B, Williams JS, Pojoga LH, Raby B, Lasky-Su J, Hunt S, Hopkins PN, Jeunemaitre X, Adler GK, Williams GH: The association of the angiotensinogen gene with insulin sensitivity in humans: A tagging single nucleotide polymorphism and haplotype approach. Metabolism 2011;60:1150-1157.

-9 Takakura Y, Yoshida T, Yoshioka K, Umekawa T, Kogure A, Toda H, Kagawa K, Fukui S, Yoshikawa T: Angiotensinogen gene polymorphism (Met235Thr) influences visceral obesity and insulin resistance in obese japanese women. Metabolism 2006;55:819-824.

10 Levesque S, Moutquin JM, Lindsay C, Roy MC, Rousseau F: Implication of an AGT haplotype in a multigene association study with pregnancy hypertension. Hypertension 2004;43:71-78.

$>11$ Irvin MR, Lynch AI, Kabagambe EK, Tiwari HK, Barzilay JI, Eckfeldt JH, Boerwinkle E, Davis BR, Ford CE, Arnett DK: Pharmacogenetic association of hypertension candidate genes with fasting glucose in the genhat study. J Hypertens 2010;28:2076-2083.

12 Jeong KH, Moon JY, Chung JH, Kim YH, Lee TW: Significant associations between CCL5 gene polymorphisms and post-transplantational diabetes mellitus in korean renal allograft recipients. Am J Nephrol 2010;32:356-361.

13 Pinzur MS, Slovenkai MP, Trepman E, Shields NN, Diabetes Committee of American Orthopaedic Foot and Ankle Society: Guidelines for diabetic foot care: Recommendations endorsed by the diabetes committee of the american orthopaedic foot and ankle society. Foot Ankle Int 2005;26:113-119. 


\section{Kidney \\ Blood Pressure Research}

\begin{tabular}{l}
\hline Kidney Blood Press Res 2013;37:95-102 \\
\hline \begin{tabular}{l|l} 
DOI: 10.1159/000343404 & $\begin{array}{l}\text { C } 2013 \text { S. Karger AG, Basel } \\
\text { www.karger.com/kbr }\end{array}$ \\
Published onlıne: March 31, 2013 &
\end{tabular}
\end{tabular}

Lee/Moon/Lee/Ihm/Lee/Kim et al.: AGT Gene Polymorphism and PTDM

14 Sumrani NB, Delaney V, Ding ZK, Davis R, Daskalakis P, Friedman EA, Butt KM, Hong JH: Diabetes mellitus after renal transplantation in the cyclosporine era - an analysis of risk factors. Transplantation 1991;51:343-347.

15 Jeunemaitre X, Soubrier F, Kotelevtsev YV, Lifton RP, Williams CS, Charru A, Hunt SC, Hopkins PN, Williams RR, Lalouel JM, et al.: Molecular basis of human hypertension: Role of angiotensinogen. Cell 1992;71:169180.

-16 Inoue I, Nakajima T, Williams CS, Quackenbush J, Puryear R, Powers M, Cheng T, Ludwig EH, Sharma AM, Hata A, Jeunemaitre X, Lalouel JM: A nucleotide substitution in the promoter of human angiotensinogen is associated with essential hypertension and affects basal transcription in vitro. J Clin Inv 1997;99:17861797.

17 Kim HS, Krege JH, Kluckman KD, Hagaman JR, Hodgin JB, Best CF, Jennette JC, Coffman TM, Maeda N, Smithies O: Genetic control of blood pressure and the angiotensinogen locus. Proc Nat Acad Sci USA 1995;92:2735-2739.

18 Mateo T, Abu Nabah YN, Abu Taha M, Mata M, Cerda-Nicolas M, Proudfoot AE, Stahl RA, Issekutz AC, Cortijo J, Morcillo EJ, Jose PJ, Sanz MJ: Angiotensin ii-induced mononuclear leukocyte interactions with arteriolar and venular endothelium are mediated by the release of different cc chemokines. J Immunol 2006;176:5577-5586.

19 Kalupahana NS, Moustaid-Moussa N: The renin-angiotensin system: A link between obesity, inflammation and insulin resistance. Obes Rev 2012;13:136-149

-20 Daimon M, Oizumi T, Saitoh T, Kameda W, Hirata A, Yamaguchi H, Ohnuma H, Igarashi M, Tominaga M, Kato $\mathrm{T}$ : The D allele of the angiotensin-converting enzyme insertion/ deletion (I/D) polymorphism is a risk factor for type 2 diabetes in a population-based japanese sample. Endocrine J 2003;50:393-398.

21 Panahloo A, Andres C, Mohamed-Ali V, Gould MM, Talmud P, Humphries SE, Yudkin JS: The insertion allele of the ACE gene I/D polymorphism. A candidate gene for insulin resistance? Circulation 1995;92:33903393.

22 Ozdemir BH, Ozdemir FN, Atac FB, Ozdemir AA, Haberal M: Angiotensinogen T235 and angiotensinconverting enzyme insertion/deletion polymorphisms associated with the development of posttransplantation diabetes mellitus in renal allograft recipients. Transplant Proc 2011;43:572-574

23 Ghisdal L, Baron C, Le Meur Y, Lionet A, Halimi JM, Rerolle JP, Glowacki F, Lebranchu Y, Drouet M, Noel C, El Housni H, Cochaux P, Wissing KM, Abramowicz D, Abramowicz M: TCF7L2 polymorphism associates with new-onset diabetes after transplantation. J Am Soc Nephrol 2009;20:2459-2467.

24 Hjelmesaeth J, Hartmann A, Kofstad J, Stenstrom J, Leivestad T, Egeland T, Fauchald P: Glucose intolerance after renal transplantation depends upon prednisolone dose and recipient age. Transplantation 1997;64:979-983.

25 Bloom RD, Rao V, Weng F, Grossman RA, Cohen D, Mange KC: Association of hepatitis c with posttransplant diabetes in renal transplant patients on tacrolimus. J Am Soc Nephrol 2002;13:1374-1380. 